\title{
DESIGN, ERGONOMIA E IMPRESSÃO 3D: UM EXERCÍCIO PRÁTICO DE PROJETO PARA PROTETORES DE TOMADA
}

\section{DESIGN, ERGONOMICS AND 3D PRINTING: A PRACTICAL EXERCISE IN PROJECT FOR OUTLETS PLUGS COVERS}

\author{
Ferdinan Sousa ${ }^{1}$ Bach \\ Nayana Gatinho ${ }^{2}$ Bach \\ André Demaison ${ }^{3,}$ M.Sc \\ Lívia Flávia Campos ${ }^{4}$, D.Sc
}

(1) Universidade Federal do Maranhão

ferdinansousa.16@gmail.com

(2) Universidade Federal do Maranhão

nayanagsilva@gmail.com

(3) Universidade Federal do Maranhão

demaison@gmail.com

(4) Universidade Federal do Maranhão

liviaflavia@gmail.com

Protetor de tomada, Design de produto, Impressão 3D

$\mathrm{O}$ estudo refere-se ao desenvolvimento de um projeto para protetores de tomada, levando em consideração critérios ergonômicos e de usabilidade. O estudo foi desenvolvido em duas disciplinas do curso de graduação em Design (Projeto de Produto 1 e Ergonomia e Projeto de Produto), ocorrendo de maneira integrada a fim de corroborar conteúdos e as práticas do design na solução de um problema. Nesse caso, o problema abordado incluiu o risco de acidentes domésticos, principalmente envolvendo crianças. O objetivo do projeto foi elaborar um novo produto mais eficiente, seguro e confortável. Para tanto, utilizou-se a metodologia de desenvolvimento de produto proposta por Lobach (2000), juntamente com ferramentas apresentadas por Baxter (2011) e Análise da Tarefa (MORAES; MONT'ALVÃO, 2000). Testes de validação como Teste de Erick (CAVALCANTI, 2003) e uma escala de satisfação (SUS) (BROOKE, 1986) foram aplicados após a impressão 3D do protótipo. O estudo resulta em uma proposta conceitual para novos protetores de tomada, que fora testado e avaliado por usuários, a partir do protótipo desenvolvido. Os critérios ergonômicos e de usabilidade neste projeto de produto norteou a escolha de alternativas, a fim de melhorar os aspectos funcionais e consequentemente a satisfação dos indivíduos.

\section{Outlets plugs covers, Product design, 3D Printing}

The study refers to the design of outlets plugs covers, taking into account ergonomic and usability criteria. The study was developed in two subjects of the Design undergraduate course (Product Design 1 and Ergonomics and Product Design), developed in an integrated way to corroborate content and design practices in solving a problem. In this case, the problem addressed included the risk of domestic accidents, especially involving children. The aim of the project was to develop a new, more efficient, safe and comfortable product. For this, we used the product development methodology proposed by Lobach (2000), together with tools presented by Baxter (2011) and Task Analysis (MORAES; MONT'ALVÃO, 2000). Validation tests such as the Erick Test (CAVALCANTI, 2003) and a Satisfaction Scale (SUS) (BROOKE, 1986) were applied after $3 D$ printing of the prototype. The study results in a conceptual proposal for new outlets plugs covers that has been tested and evaluated by users from the developed prototype. The ergonomic and usability criteria in this product project guided the choice of alternatives in order to improve functional aspects and, consequently, the satisfaction of individuals. 


\section{Introdução}

Com o advento da eletricidade, os eletrodomésticos passaram a fazer parte da vida das pessoas e, consequentemente, as tomadas elétricas também. Com a presença das tomadas domésticas acidentes elétricos começaram a acontecer. De acordo com Malacarne (2016), a curiosidade das crianças pode levá-las a algumas situações perigosas principalmente perto de objetos relacionados à eletricidade como fios, cabos e tomadas. Segundo a ABRACOPEL (Associação Brasileira de Conscientização para os Perigos da Eletricidade), no ano de 2018, os eventos com choque elétrico lideram o ranking de acidentes de origem elétrica no país, com 836 registros de casos fatais e não fatais. Entre as vítimas fatais de choques elétricos encontram-se as crianças de 0 a 10 anos, as quais somaram 34 vítimas (5\%), sendo 20 delas de 0 a 5 $\operatorname{anos}(3 \%)$.

Os protetores para tomadas residenciais surgiram a partir da necessidade de impedir o contato acidental com a corrente elétrica, principalmente por crianças. Considerando o crescimento na indústria de eletrodomésticos e as mudanças e adaptações para os plugues, nota-se que os protetores de tomada acompanham esse fluxo. Percebe-se que o seu desenho segue os desenhos dos espelhos das tomadas, possuindo formas redondas, quadradas ou retangulares, além disso, podem possuir pinos chatos ou pinos cilíndricos, que também simulam as formas dos plugues. Mesmo com essa evolução no ambiente doméstico devido aos vários modelos de protetores já disponibilizados no mercado, com o incentivo de utilização desses produtos, com o investimento na publicidade para alavancar as vendas e com o aumento de informações alertando pais e responsáveis sobre o uso dos protetores, nota-se que acidentes relacionados ao contato acidental com a rede elétrica ainda ocorrem. Dados da ABRACOPEL apresentaram em 2018, que nos ambientes residenciais (somatória de unifamiliar+multifamiliar+sítios e fazendas) foram registradas 209 mortes, superando os acidentes que envolvem as redes aéreas de distribuição (172).

Assim, o objetivo do presente estudo foi investigar aspectos relevantes para desenvolver novos protetores de tomadas mais eficientes, confortáveis e seguros para os usuários.

\section{Risco e perigo do choque elétrico em ambiente doméstico}

Segundo Sanders e McCormick (1993, p. 675), "risco é a probabilidade ou chance de lesão ou morte". Já o perigo consiste em "[...] uma condição ou um conjunto de circunstâncias que têm o potencial de causar ou contribuir para uma lesão ou morte".

A Norma Regulamentadora No 10 (ABNT, 2004, p. 9) define perigo como "situação ou condição de risco com probabilidade de causar lesão física ou danos à saúde das pessoas por ausência de medidas de controle". E risco, a "capacidade de uma grandeza com potencial para causar lesões ou danos à saúde das pessoas".

Assim, no ambiente doméstico o risco de danos à saúde em virtude de acidentes envolvendo eletricidade é uma condição real e que merece atenção, principalmente quando há a presença de crianças na fase pré-escolar. Segundo Bezerra et. al (2014), nesta fase as causas externas são as mais responsáveis pelas lesões e óbitos que acometem crianças no Brasil e no mundo. Isto se deve ao conjunto de características que as tornam mais vulneráveis aos acidentes, como a imaturidade física, mental e comportamental. As crianças ficam mais propensas aos acidentes em ambiente doméstico, dentre eles o choque dinâmico, o qual segundo a classificação de Kindermann (2000), é aquele decorrente do contato direto (com um circuito energizado) ao se tocar acidentalmente na parte viva de um condutor energizado nu ou com defeito, fissura ou rachadura na isolação, queda de condutor da rede de energia elétrica, etc.; ou no contato indireto (com um corpo/massa eletrizado), ao se tocar nas massas (carcaças) energizadas por defeitos como fissura na isolação dos condutores elétricos;

Segundo Malacarne (2016), dentro de casa, os maiores perigos são as tomadas sem proteção, fios desencapados e benjamins ("Ts"). Além de outras medidas, o uso de protetores de tomadas ainda é bastante recomendado por especialistas.

\section{Métodos e Técnicas}

Segundo Bomfim (1995), a metodologia é o estudo dos métodos, técnicas e ferramentas e de suas aplicações à definição, organização e solução de problemas teóricos e práticos. 
PUC-Rio Pontifícia Universidade Católica do Rio de Janeiro Departamento de Artes \& Design | PPGDesign

Para o presente estudo, fez-se uso da metodologia projetual de Bernd Löbach (2000). Em sua proposta, o autor aponta que o processo de design é tanto um processo criativo como de solução de problemas e referência a lógica de avanços e retrocessos ao longo do processo de design, dividindo seu método em quatro fases: fase de preparação; fase de geração; fase de avaliação e fase de realização. Essas etapas nortearam todo o processo de desenvolvimento deste projeto.

A ergonomia também usa métodos e técnicas para observar o trabalho humano. Para realizar qualquer tarefa, o ambiente físico precisa estar adequado e em condições para receber o produto, evitando, assim resultados despropositados. Para o desenvolvimento de produtos, há uma vasta quantidade de métodos e técnicas que visam resolver os problemas e questões que envolvem o entorno material dos produtos existentes.

Fase de preparação - Na referida fase, inicia-se o processo de solução e o processo de design para desenvolvimento do produto. Segundo Lobach (2000), para primeira fase é essencial a coleta máxima de informações possíveis para que se possa prepará-las para a fase posterior. Aqui foram aplicadas as técnicas utilizadas para o desenvolvimento do projeto de produto (LOBACH, 2000) como a Análise da Necessidade, Análise Comparativa do Produto, Análise de Público Alvo, Análise do Mercado, além de técnicas da ergonomia como a Sistematização Homem-Tarefa-Máquina, Fluxograma da Tarefa, para a realização da apreciação ergonômica (MORAES E MONT'ALVÃ̃, 2000); para os testes de verificação utilizou-se os Testes de Usabilidade e Teste de Erick (CAVALCANTI, 2002), e por fim, para Análise de Satisfação, aplicou-se o questionário SUS - System Usability Scale (BROOKE, 1986).

Fase de Geração - Após a fase de preparação, na qual se analisa o problema com seu entorno, ocorre a segunda fase, na qual são geradas as alternativas para o mesmo (LOBACH, 2000). O autor afirma que nesta fase de produção de ideias, para que se possa gerar o maior número de alternativas possíveis, a mente precisa trabalhar livremente, sem restrições. Partindo desse princípio, fez-se uso das técnicas de Moodboard (MCDONAGH E DENTON, 2005), Mapa Mental (BUZAN, 2005), Brainstorming (VIANNA et al., 2012) e Brainwriting (MICHINOV, 2012), a fim de estimular a criatividade na geração de ideias.
Fase de Avaliação - A partir das alternativas elaboradas, foi possível encontrar a solução mais plausível diante dos critérios elaborados previamente (LOBACH, 2000). Para isso, foi gerado um produto conceito e desenvolvido um mockup, a fim de definir as dimensões do produto, levando em consideração os princípios da antropometria (PASCHOARELLI, 2000) e da biomecânica (IIDA 2005).

Fase de realização - Esta etapa foi a materialização da alternativa escolhida. Lobach (2000) afirma que a melhor alternativa apresentada na forma de um produto industrial, se converte então em um protótipo. Para tanto, foi elaborado o desenho técnico e modelagem digital do produto, e por fim a prototipação a através do uso da tecnologia de impressão 3D.

Validação - Esta etapa foi incluída a fim de corroborar os atributos referente a funções e satisfação do usuário, onde foram aplicados novamente os testes de Usabilidade, Teste de Erick e o questionário SUS, com o protótipo do novo produto desenvolvido.

\subsection{Fase de Preparação \\ 3.1.1 Análise de Necessidade}

Dados recentes apontam que o número de acidentes elétricos ainda ocorre dentro do ambiente doméstico, mesmo com a normatização, a evolução das tomadas e os meios criados como forma de prevenção aos riscos de choques elétricos, portanto o produto ainda se mostra como uma importante ferramenta para proteção das crianças. Segundo levantamento da ABRACOPEL em 2018 entre as vítimas fatais de choques elétricos as crianças de 0 a 10 anos somaram 34 vítimas (5\%), sendo 20 delas de 0 a 5 $\operatorname{anos}(3 \%)$.

\subsection{Análise Comparativa do Produto}

Foi realizada uma pesquisa em lojas físicas e online para analisar os protetores de tomada já disponibilizados no mercado, com foco nos modelos utilizados para o novo padrão de tomadas, o modelo de três pinos que entrou em vigência no cenário brasileiro a partir de 2012 .

Foram encontradas quatro opções relevantes (tabela 1) de acordo com as características definidas para análise sendo elas modelos adequados para o novo 
padrão de tomada e produzidos a partir do polipropileno.

Tabela 1 - análise de similares

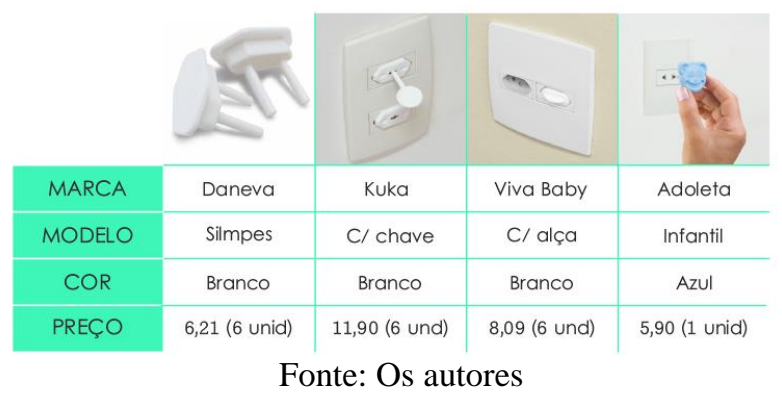

\subsection{Público Alvo}

Para a definição e entendimento de consumo do público-alvo, fez-se a aplicação de um questionário online e entrevistas presenciais, que totalizaram um número de 40 entrevistados entre 18 a 56 anos, a fim de conhecer os usuários do produto.

Através desse levantamento, concluiu-se que existem mais de um público direto, são eles: pais/ mães e crianças na faixa etária de 1 a 4 anos; e um público indireto, familiares e babás. A procura e utilização dos produtos é dada, na maioria das vezes, por um público feminino, o que correspondeu a $71 \%$ dos entrevistados. A maioria dos usuários (87\%) que utilizam os protetores, residem com criança (s) e afirmam só usarem até os primeiros 4 anos de idade. E quando não há criança pequena no domicílio, ocorre o desuso do acessório.

\subsection{Análise de Mercado}

Também com base nos questionários e nas entrevistas, constatou-se que o modelo mais utilizado para proteger as tomadas é o modelo simples (Figura 1), de superfície plana e sem presença de componentes como chaves $(46,2 \%)$, além disso, os entrevistados relataram que este seria o modelo mais barato mais encontrado no mercado.

\author{
Figura 1 - Protetor Universal para Tomadas \\ (modelo simples)
}

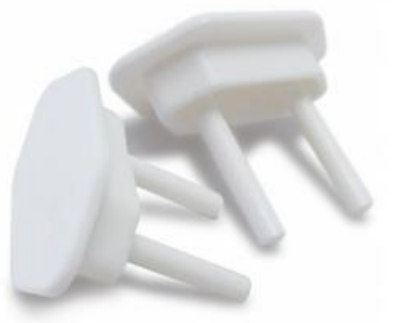

Fonte: Magazineluiza.com.br

Alguns entrevistados afirmaram que não utilizavam os protetores (41\%), e os principais motivos para isso seriam a ausência de crianças pequenas na residência ou por possuírem apenas tomadas altas em casa. Alguns entrevistados relataram ainda, que faziam o uso de produtos alternativos para a proteção das tomadas, como o uso de fita isolante, por exemplo. Outros afirmaram que vigiavam a criança de modo que não viam necessidade de uso do produto. Por fim, havia aqueles que vivenciaram algum tipo de frustração em relação ao uso do produto, como a dualidade de dificuldade de um adulto para remover o acessório e a facilidade da criança para remover o protetor da tomada. A maior parte dos entrevistados (59\%) afirmou não ter dificuldade de encontrar protetores de tomadas no mercado e $77 \%$ afirmou que não consideravam um produto caro.

\subsubsection{Sistema-Homem-Tarefa-Máquina (SHTM)}

Nessa fase inicial, de análise do problema, realizouse uma apreciação ergonômica, com a

Sistematização Homem-Tarefa-Máquina, proposta por Moraes e Mont'Alvão (2000). Essa etapa consiste na apresentação ilustrada do problema através da elaboração de quadros, tabelas e fluxogramas. Nessa sistematização cabe enfatizar a interação entre homens e máquinas. Entende-se por máquina tudo aquilo que compreende qualquer mecanismo com o qual o usuário executa uma atividade com um dado propósito. (BRANDÃO, 2012).

Na sistematização, o sistema alvo foi o uso do protetor de tomada e a meta do sistema foi proteger o usuário contra choques elétricos. $\mathrm{O}$ esquema e sua hierarquia podem ser observado nas Figuras 2 e 3. 
Figura 2 - Sistema Homem Tarefa Máquina do uso de protetores de tomada

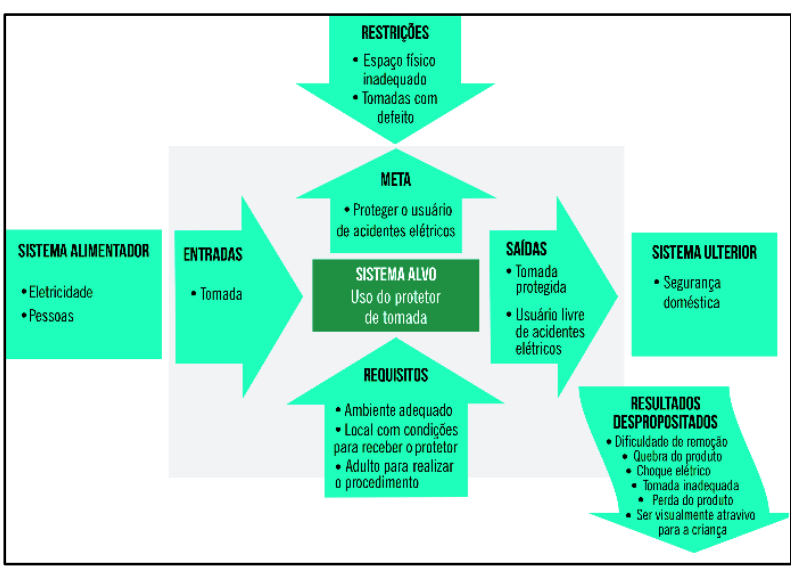

Fonte: Os autores

Figura 3 - Hierarquia do Sistema Homem Tarefa Máquina

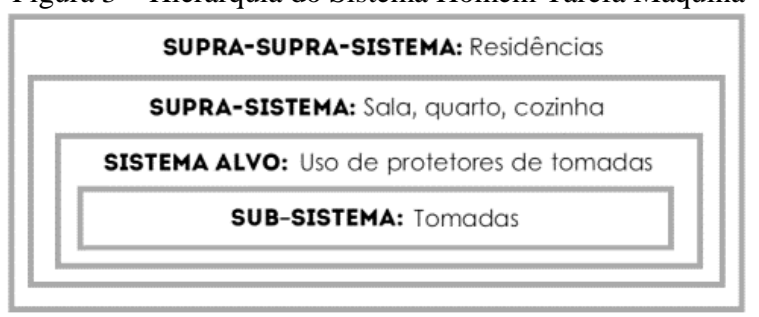

Fonte: Os autores

A partir da Sistematização, foi possível visualizar e organizar uma série de fatores para melhorar o conhecimento do produto e a compreensão do problema.

\subsubsection{Fluxograma da tarefa}

Realizou-se uma simulação de uso, registrada por meio de fotografias, de todas as etapas de utilização do protetor de tomada realizada, desde a retirada de um plugue receptor de energia elétrica até a realocação do mesmo. Visou-se compreender todos os componentes da tarefa e identificar as possíveis falhas nesse sistema. A partir da simulação da utilização do protetor de tomada, criou-se um fluxograma detalhado da tarefa.
Figura 4 - Simulação da utilização do protetor de tomada

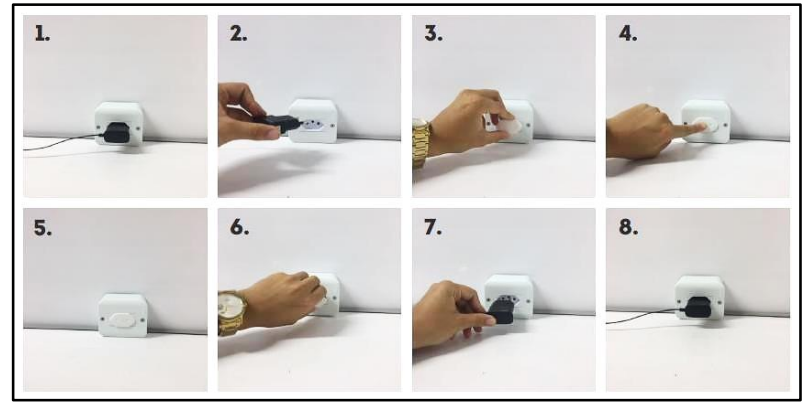

Fonte: Os autores

Figura 5 - Fluxograma detalhado da tarefa do uso do protetor de tomada simples

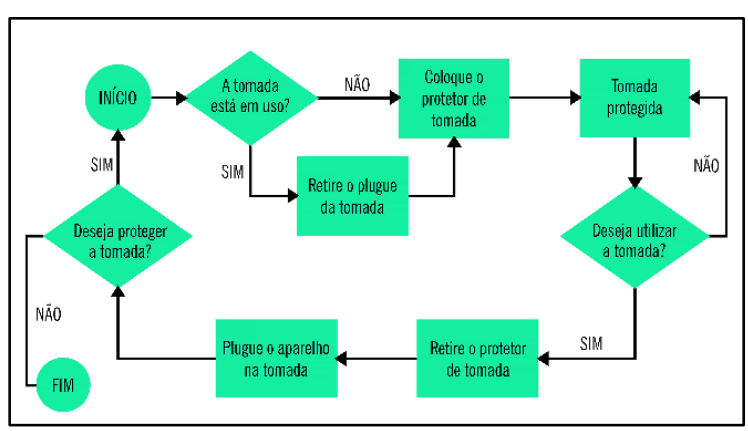

Fonte: Os autores

\subsubsection{Teste de Usabilidade e Teste de Erick}

Com intuito de verificar outras possíveis formas de utilização e validar o fluxo real que os usuários realizam para utilização do protetor de tomada, decidiu-se aplicar um teste de usabilidade, onde os usuários simularam a utilização de uma tomada, fazendo o uso de um carregador de celular e de um protetor de tomada.

Decidiu-se aplicar em paralelo aos testes de usabilidade outro método, denominado Teste de Erick (Cavalcanti, 2002). O teste consistiu em identificar a principal região de contato, a partir da aplicação de uma camada de tinta sob a superfície do produto e posterior impressão da mancha gerada, em uma folha de papel. 
Figura 6 - Fluxograma detalhado da tarefa do uso do protetor de tomada simples

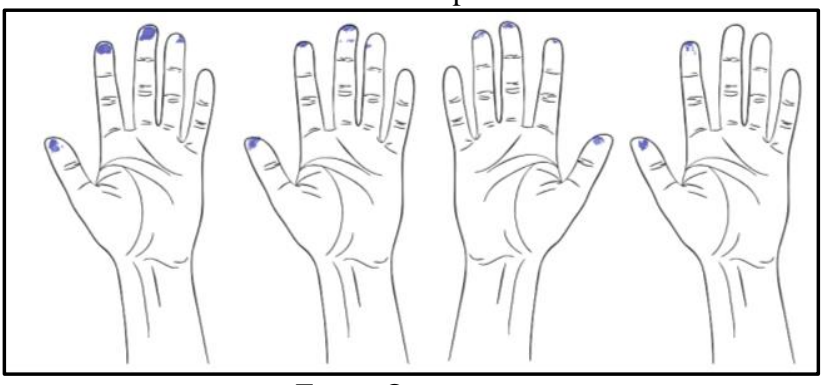

Fonte: Os autores

O teste foi aplicado com cinco mulheres, sendo elas mães e pessoas que fazem o uso de protetores em suas casas, devido a presença de crianças no ambiente doméstico. Com o teste, foi possível confirmar o fluxo da tarefa executada, sem muitas diferenças pelos usuários, e também identificar as áreas da mão mais utilizadas pelo usuário para fazer o manuseio do produto (figura 6). Observou-se que os dedos utilizados para remover o produto são: 0 polegar, o indicador, o médio e o anelar, mas alguns usuários utilizam apenas o polegar e o indicador. Além disso, a parte dos dedos que faz contato com a área de pega do produto são apenas as falanges. Nota-se que a área de pega é pequena. Isso se dá pela superfície estreita que o produto apresenta como área de contato para o usuário.

\subsubsection{Análise de Satisfação - SUS}

Após a aplicação dos testes anteriores optou-se por aplicar a escala SUS - System Usability Scale, método de averiguação do nível de usabilidade em relação ao uso de um determinado produto ou sistema. Proposto por Brooke (1986), o método pretende avaliar aspectos como efetividade, eficiência e satisfação. O questionário SUS consiste em dez perguntas por padrão, sendo elas aqui apenas adaptadas ao contexto do produto em questão. Depois da explicação dos objetivos do teste, os usuários responderam o questionário, contendo as seguintes perguntas:

1. Eu acho que gostaria de usar esse produto de tomada com frequência.

2. Eu acho o produto desnecessariamente complexo.

3. Eu achei o produto fácil de usar.

4. Eu acho que precisaria de ajuda de uma pessoa com conhecimentos técnicos para usar o produto.

5. Eu acho que as várias funções do produto estão muito bem integradas.

6. Eu acho que o produto apresenta muita inconsistência.
7. Eu imagino que as pessoas aprenderão como usar esse produto rapidamente.

8. Eu achei o produto atrapalhado de usar.

9. Eu me senti confiante ao usar o produto.

10. Eu precisei aprender várias coisas novas antes de conseguir usar o produto.

As respostas são obtidas por meio de uma escala entre 1 e 5 , onde 1 equivale a "discordo completamente" e 5 equivale a "concordo completamente. As respostas são mensuradas a partir do seguinte cálculo: para as perguntas ímpares subtrai-se 1 da resposta dada pelo usuário e para as perguntas pares subtrai-se a resposta do usuário por 5. Em seguida, faz-se a soma dos valores obtidos e multiplica-se por 2.5. A pontuação final pode variar entre 0 e 100 pontos, sendo a média aceitável de 68 pontos, ou seja, pontuações menores apontam para sérios problemas de usabilidade, já as maiores apontam para bons aspectos positivos.

O teste também foi realizado pelas cinco mães que participaram dos testes anteriores. A média dos resultados obtidos nos questionários foi 67.5 , o que implica afirmar que o produto possui problemas de usabilidade.

\subsubsection{Normas}

Cada norma técnica geralmente trata de um assunto específico. Por isso, quando é definido um padrão, como o dos plugues e tomadas, ele é geralmente formado por um conjunto delas, cada qual atendendo um aspecto como proteção, isolação, durabilidade, adaptações, dimensões físicas, materiais utilizados, etc.

A norma utilizada como referência foi NBR 14136, que foi proposta em 1989 e aprovada em 2000, entrando em vigor no Brasil em 2012. A norma foi usada para entender o novo padrão para assim ser possível construir o produto de acordo com o objetivo de atender o público brasileiro.

\subsection{Fase de Geração}

Nesta etapa é feita a escolha de métodos para solucionar problemas, produção e geração de ideias. São propostas alternativas de solução utilizando conceitos de design, esboços de ideias e modelos.

Para auxiliar nesse processo fez-se o uso de técnicas de criatividade desenvolvidas para implementar a geração de ideias. As técnicas de criatividade são 
PUC-Rio Pontifícia Universidade Católica do Rio de Janeiro Departamento de Artes \& Design | PPGDesign

LEUI | Laboratório de Ergodesign e Usabilidade de Interfaces

atividades desenvolvidas com um conjunto de pessoas para a definição de um problema, avaliação, seleção, implementação de ideias e geração de ideias criativas e inovadoras.

\subsubsection{Moodboard}

Segundo McDonagh e Denton (2005), os moodboards geralmente são configurados por uma compilação de elementos visuais com o intuito de estimular a comunicação e o desenvolvimento no processo de design. O moodboard do público alvo, também conhecido como Painel Semântico, foi construído a partir do perfil da persona gerada. Nele se mostraram presentes elementos da rotina de uma mãe com seu filho, a personalidade das crianças unido à um estilo de vida saudável, ligado à natureza, representados por uma paleta de cores vibrantes e bastante saturadas. Os personagens presentes na rotina da persona criada, marido, filho, cachorro, também fizeram parte da composição.

Pode-se observar o resultado do moodboard na Figura 7.

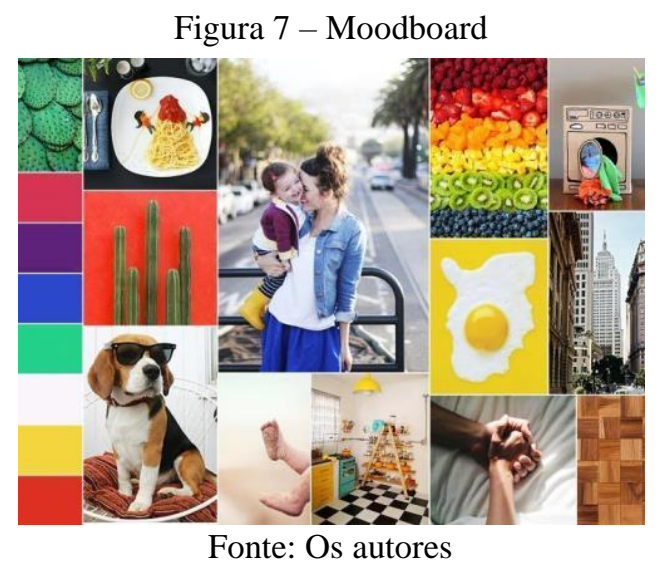

\subsubsection{Mapa Mental}

Os mapas são estruturas radiais, o que significa que as informações neles contidas são dispostas em raios. A origem para essa representação radial está, segundo Buzan (2005), na forma como o cérebro funciona, já que pessoas pensam radialmente.

Buzan (2005) propõe que o mapa mental use cores, tenha uma estrutura natural que parte do centro, utilize linhas curvas, símbolos, palavras, imagens, opere em harmonia com o cérebro e possua ramificações orgânicas que estimulem os olhos. Para o autor, o mapa mental é o reflexo dos processos e capacidades de pensamento tanto naturais como imagéticos do cérebro. A Figura 8 demonstra a aplicação desse método, como estímulo para a geração de ideias do produto em estudo.

Figura 8 - Mapa mental elaborado para solucionar problemas do produto

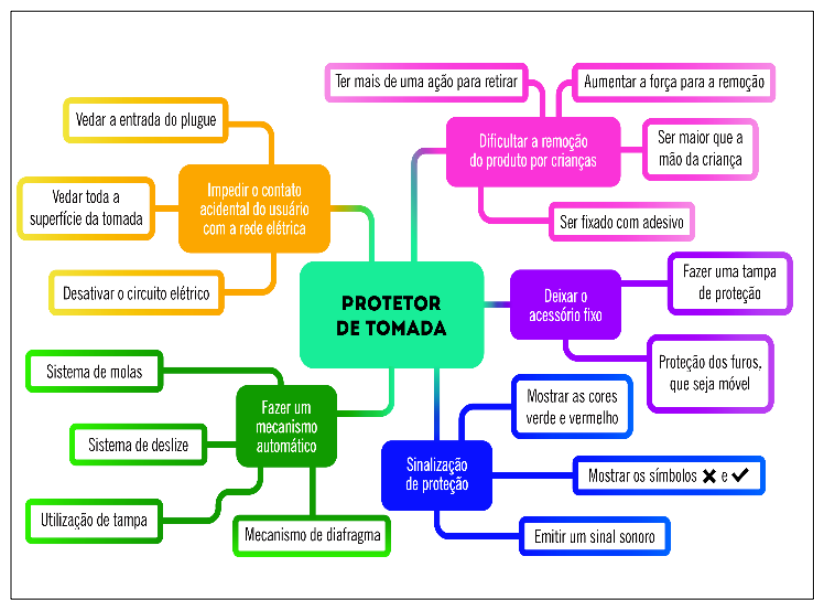

Fonte: Os autores

\subsubsection{Brainstorming e Brainwriting}

Segundo Vianna et al. (2012) a técnica de brainstorming é utilizada para estimular o surgimento do maior número possível de ideias em um espaço pequeno de tempo. O brainstorming foi realizado mais de uma vez, com intervalos propositais para pensar em soluções alternativas com base em coisas do cotidiano. A partir dessas, outro brainstorming foi elaborado a fim de tornar visível as propostas de soluções geradas e estimular novas ideias a partir delas. Com o objetivo de gerar o máximo de ideias, durante a realização da técnica houve a tentativa de não pensar precocemente em requisitos projetuais ou qualquer fator delimitante. Além disso, não foi acordado entre os participantes que não houvesse nenhum tipo de crítica ou julgamento, para assim fazer o aproveitar ao máximo as ideias e tentar imaginar conexões entre todas as alternativas sugeridas. Ao final, fez-se um debate, a partir das ideias apresentadas, que resultou em novas soluções para o problema apresentado.

O brainwriting é uma técnica similar ao brainstorming, usada para fomentar a geração de ideias (MICHINOV, 2012). Diferenciando-se do brainstorming, no brainwriting os participantes não verbalizam suas ideias, elas são representadas em um papel. Ao final, as ideias de cada participante são apresentadas aos componentes do grupo para serem analisadas por todos, discutidas e incrementadas. $\mathrm{O}$ resultado do brainwriting realizado pode ser observado na Figura 9. 
Figura 9 - Rascunhos do processo de brainwritin

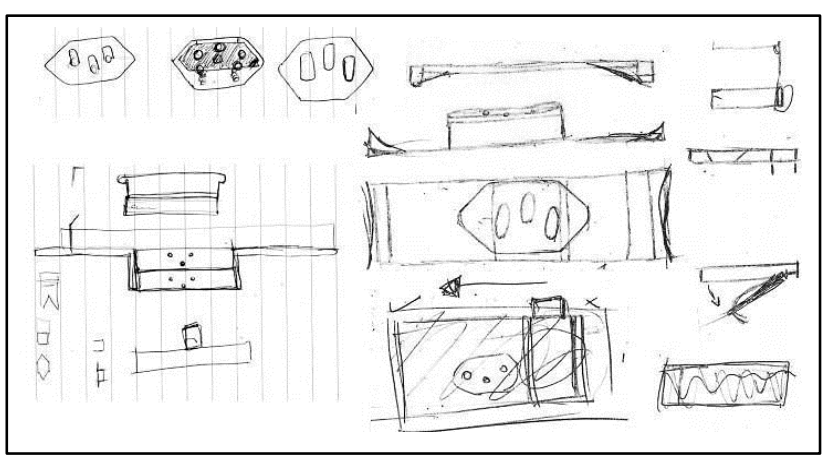

Fonte: Os autores

\subsection{Fase de Avaliação}

Nesta etapa, é feita a avaliação de alternativas de design e escolha da melhor solução. A partir dos dados coletados, foi possível chegar a um modelo conceito para o novo produto. Nesta fase, foi feito o mockup utilizando massa epóxi para dimensionar o modelo, principalmente as áreas de pega do produto.

\subsubsection{Produto Conceito}

A proposta permitir que o produto proporcione segurança ao usuário e assim possa garantir uma melhor experiência. Sendo assim, o novo modelo (Figura 10) segue a premissa de que o usuário poderá utilizar a tomada sem a necessidade de remover o protetor. Dentre suas principais características estão uma área de pega lateral maior e rugosa, garantindo mais firmeza para manusear o produto; um mecanismo semiautomático de bloqueio, composto por placas e molas, onde os orifícios da tomada ficariam bloqueados e para o uso, o usuário colocaria os pinos no orifício do próprio acessório e com um movimento de deslize para baixo ocasionaria no acesso dos pinos à tomada; além disso, é desejável uma superfície autocolante para melhor fixação à tomada, para prevenir ainda mais a remoção acidental por crianças.

Figura 10 - Produto conceito

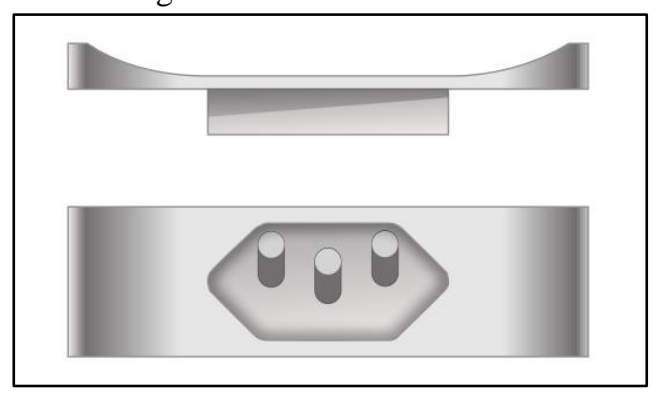

Fonte: Os autores

\subsubsection{Mockup do produto}

Inicialmente foi produzido um mockup utilizando massa epóxi, para checar o dimensionamento preliminar do modelo, principalmente para as áreas de pega. Para a concepção desse mockup foram observadas as medidas antropométricas, coletados da tabela de Pheasant (1996) apresentada por Paschoarelli (2000), como a largura do polegar, largura do dedo indicador e abertura funcional máxima de homens e mulheres, considerando os percentis 5 e 95 de ambos (Tabela 2).

Tabela 2 - Estimativa antropométrica das mãos relevantes ao projeto

\begin{tabular}{|c|c|c|c|c|}
\hline $\begin{array}{c}\text { DADOS } \\
\text { ANTROPOMÉTRICOS } \\
(\mathrm{mm})\end{array}$ & \multicolumn{2}{c|}{ HOMEM } & \multicolumn{2}{c|}{ MULHER } \\
\hline $\begin{array}{c}\text { VARIÁVEIS } \\
\text { P }\end{array}$ & P 95 & P 05 & P 95 \\
\hline Largura do polegar & 20 & 26 & 17 & 21 \\
\hline Largura do dedo indicador & 19 & 23 & 16 & 20 \\
\hline Abertura funcional máxima & 122 & 162 & 109 & 145 \\
\hline
\end{tabular}

Fonte: Adaptada de Pheasant (1996)

Além disso, considerou-se aspectos relacionados às posturas do punho e da mão. A localização e o tamanho do objeto alteram a postura do punho e dos dedos, modificando a posição do usuário em relação ao objeto. No estudo da biomecânica observa-se que vários movimentos podem ser identificados para desempenhar atividades da vida diária. De acordo com IIDA (2005), a preensão é aliada à aplicação de força muscular, permitindo a realização de tarefas. $\mathrm{O}$ tipo de pega identificado na tarefa é a Pega de Precisão ou Movimento de Pinça (IIDA, 2005), onde a mão envolve o equipamento, no caso o protetor, em um sistema de pinça entre os dedos e o polegar.

As dimensões utilizadas para a concepção da área de pega do mockup (Figura 11) foram a de $7 \times 23 \mathrm{~mm}$, devido a variante do dedo indicador de homens do percentil 95. O comprimento total do produto é de $80 \mathrm{~mm}$, tamanho que está dentro dos parâmetros de abertura funcional máxima dos percentis 5 e 95 de homens e mulheres. Além disso, é um tamanho que permite um encaixe ideal à superfície de espelhos de tomadas bastante comuns, encontradas em ambientes domésticos. As outras medidas, como os orifícios internos e angulação das bordas da parte interna, seguiram a norma de padronização de plugues de tomadas, a NBR 14136/02. 
Figura 11 - Mockup do produto conceito

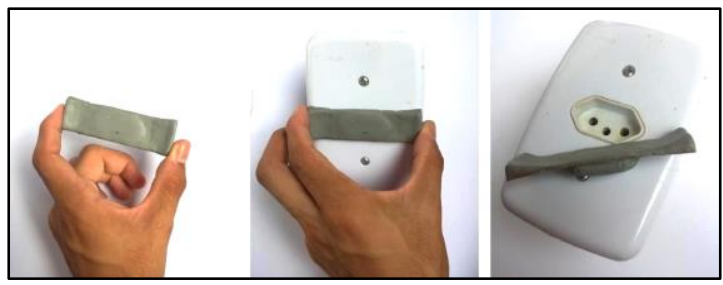

Fonte: Os autores

\subsection{Fase de Realização}

O último passo desse processo, conforme Lobach (2000), é a materialização da alternativa escolhida. Ela deve ser revista mais uma vez, retocada e aperfeiçoada. Para tanto, foi desenvolvido o desenho técnico, modelagem e prototipação do produto conceito.

\subsubsection{Desenho Técnico e Modelagem 3D}

Com base no mockup e com o auxílio de softwares como AutoCAD e SketchUp, desenvolveu-se o desenho técnico (figura 12) e em seguida, o modelo em 3D do projeto (figura 13 e 14).

Figura 12 - Desenho técnico do produto conceito

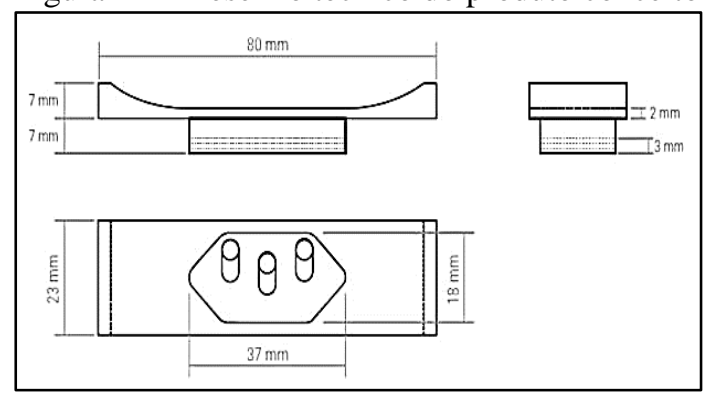

Fonte: Os autores

Figura 13 - Modelagem do produto conceito

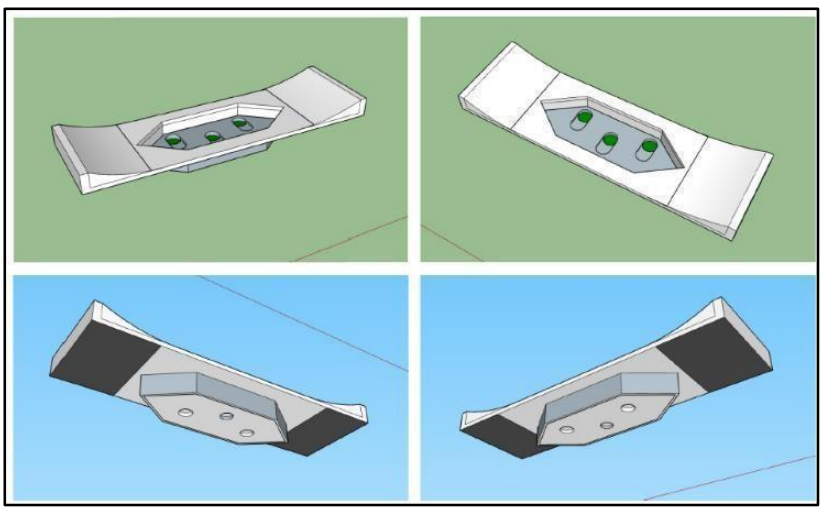

Fonte: Os autores
Figura 14 - Visão explodida do produto conceito

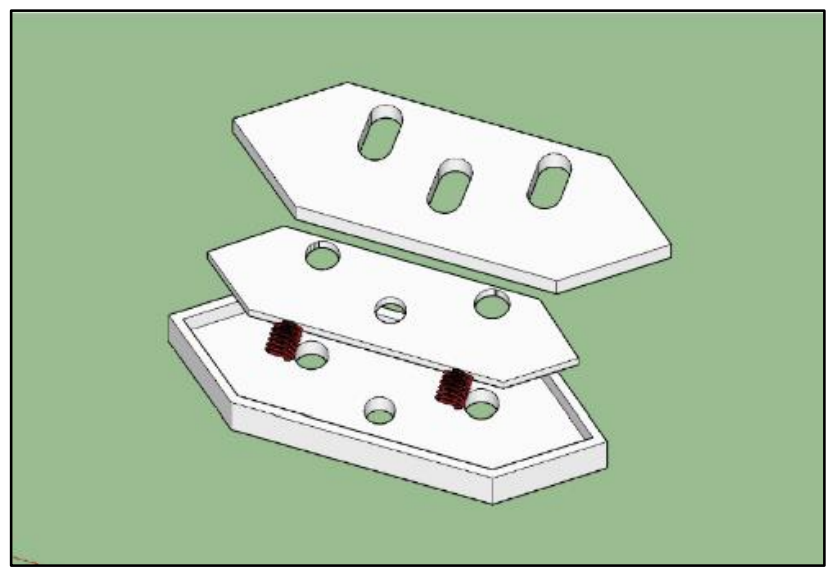

Fonte: Os autores

\subsubsection{Impressão 3D}

A partir do modelo 3D digital desenvolvido foi possível desenvolver o protótipo utilizando a impressora Ultimaker (figura 15) em um dos laboratórios de produto, dentro da universidade. Devido a algumas restrições da impressão 3D, optou-se por imprimir as partes do protótipo separadamente, conforme mostra a figura 16, e unilas posteriormente. As dimensões utilizadas foram as mesmas estabelecidas pelo projeto, em escala real e o material utilizado foi o polímero acrilonitrila butadieno estireno, conhecido como ABS. O material permitia o uso do protótipo em ambiente real por não apresentar riscos em caso de contato com a rede elétrica.

Figura 15 - Impressora 3D Ultimaker

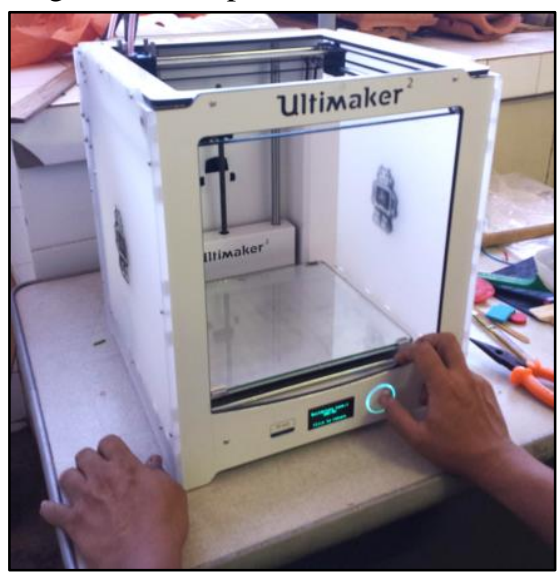

Fonte: Os autores 
Figura 16 - Partes do protótipo impressas

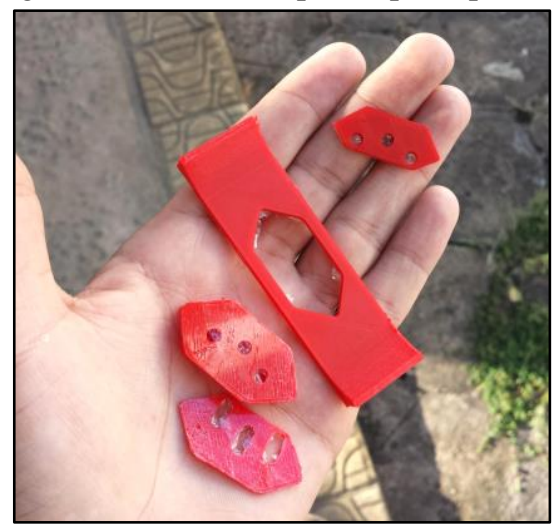

Fonte: Os autores

\subsection{Validação}

\subsubsection{Teste de Usabilidade e Fluxograma da Tarefa}

Para validar o protótipo (Figura 17), optou-se por realizar um novo teste de usabilidade. Os testes foram realizados com 6 pessoas, sendo elas 2 homens e 4 mulheres, entre 19 e 33 anos de idade. Para esta fase, não foram consideradas apenas as mães, como no teste anterior, mas pessoas que fazem parte do público-alvo indireto, com diferentes faixas etárias. O teste foi realizado com o protótipo gerado por meio da impressão 3D.

Figura 17 - Protótipo do produto conceito

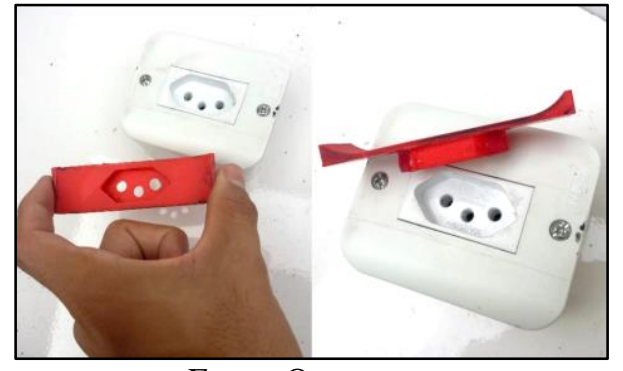

Fonte: Os autores

Após a explicação do conceito e funcionamento do mecanismo do produto, foi proposta aos avaliados a realização da tarefa, que consiste em usar a tomada, protegê-la e fazer o uso dela novamente, enquanto o tempo era cronometrado. Para facilitar o entendimento dos usuários, foi apresentado o fluxograma, ilustrado na Figura 18, para a execução do teste.
Figura 18 - Fluxograma detalhado da tarefa do produto conceito

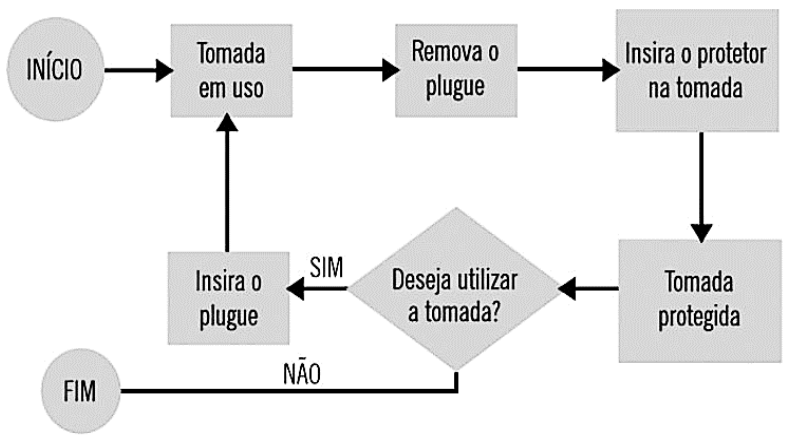

Fonte: Elaborado pelos autores

O tempo gasto pelos usuários com a simulação do uso do protótipo variou entre 10 e 15 segundos. A área de pega do produto foi facilmente reconhecida pelos usuários e a maioria dos usuários utilizou apenas uma das mãos, em movimento de pinça, para remover o produto. Em alguns casos, a forte aderência da fita utilizada e os cantos retos do protótipo impresso foram os poucos fatores que dificultaram a remoção do acessório.

\subsubsection{Validação de Satisfação - SUS}

Para mensurar a satisfação dos usuários em relação ao novo produto, aplicou-se novamente, após os testes de usabilidade, o questionário SUS.

Como resultado, obteve-se como menor média a pontuação de 77.5 , sendo todas as outras superiores ou igual a 92.5, chegando a atingir a pontuação máxima de 100 pontos. Todas as pontuações ultrapassaram a média de 68 pontos, ou seja, os dados não apontam para problemáticas na usabilidade do produto.

\subsubsection{Teste de Erick com o protótipo}

Após o questionário SUS, como último método de avaliação do protótipo, aplicou-se novamente o Teste de Erick para verificação das dimensões propostas para a área de pega utilizadas para a remoção do produto. Como mostra a Figura 19, os dedos utilizados continuam sendo principalmente $o$ polegar e o indicador, entretanto a área de contato aumentou significativamente, se comparada com o teste realizado com o protetor de tomadas simples (Figura 6). Este aumento da área de pega, garantiu aos usuários uma maior facilidade de remoção do produto, visto que a quantidade de tentativas para remoção do produto diminuiu significantemente. 
Figura 19 - Resultados do Teste de Erick aplicados com o protótipo

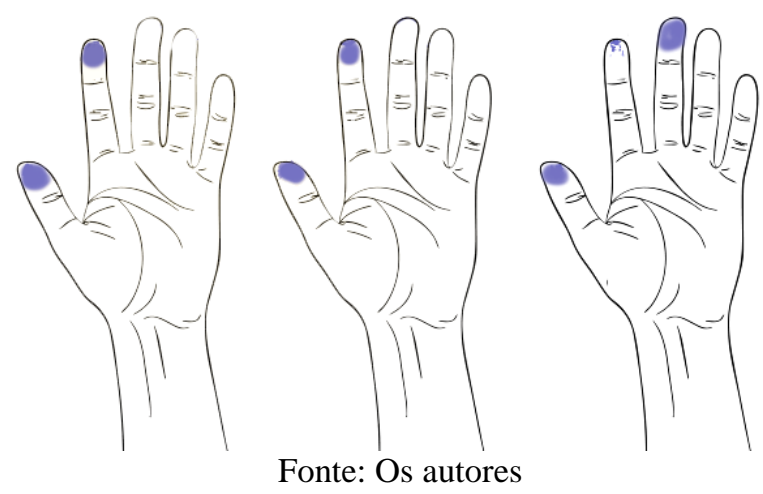

\section{Considerações Finais}

Os protetores de tomada ainda são acessórios de extrema importância para diminuir riscos de acidentes elétricos no ambiente doméstico. Entretanto, verificou-se na pesquisa que eles são pouco utilizados por não atenderem às necessidades do usuário de forma eficiente. A partir das entrevistas, notou-se que os usuários recorrem a alternativas como o uso de fitas adesivas, reposicionamento de móveis, para servir de obstáculo e até mesmo isolar ambientes inteiros como quartos que possuem tomadas elétricas posicionadas abaixo de 1 metro de altura, para assim afastar crianças pequenas do risco de acidente devido ao contato direto com esses canais de corrente elétrica.

O projeto buscou abordar este problema a partir do desenvolvimento de um novo produto, visando garantir ao usuário maior conforto e segurança, a partir de um sistema semiautomático para isolar os orifícios da tomada, diminuindo as fases da realização da tarefa. Além disso, buscou-se aumentar a área de contato lateral do produto, para garantir uma remoção mais fácil, por adultos, quando necessária.

A estratégia para dificultar a remoção acidental do acessório, por crianças foi projetar a área de pega maior, nas extremidades laterais do produto, sabendo que a abertura funcional das crianças é menor que as medidas do comprimento total do protetor de tomada proposto. Os testes realizados mostram que houve a melhora dos problemas identificados e o aumento significante da satisfação dos usuários devido a melhor experiência com o uso do acessório. No geral, o projeto se apresenta como uma alternativa satisfatória para o desenvolvimento de um novo modelo de protetor de tomadas.

Além disso, destaca-se aqui a importante integração entre as disciplinas de Projeto de Produto e Ergonomia, as quais aliadas à tecnologia de impressão 3D, permitiram aos discentes a experiência de desenvolver um projeto para um problema real, desde a análise do problema até a validação da alternativa desenvolvida.

\section{Referências}

ABNT. NBR 14136: Plugues e tomadas para uso doméstico e análogo até $20 \mathrm{~A} / 250 \mathrm{~V}$ em corrente alternada - Padronização. 2 ed. Rio de Janeiro: Associação Brasileira de Normas Técnicas, 2012.

ABNT. NR 10: Segurança em instalações e serviços em eletricidade. Rio de Janeiro: Associação Brasileira de Normas Técnicas, 2004.

ABRACOPEL. Anuário Estatístico Abrocopel: Acidentes de Origem Elétrica 2019 (ano base 2018). 2019. Disponível em: <http://abracopel.org/wpcontent/uploads/2019/05/Anu\%C3\% A1rioABRACOPEL-2019.pdf >. Acesso em: 21 de abril de 2019.

BAXTER, Mike. Projeto de Produto: Guia prático para o design de novos produtos. 2. ed. São Paulo: Editora Blucher, 2005.

BAXTER, Mike. Projeto de Produto: Guia prático para o design de novos produtos. 3. ed. São Paulo: Editora Blucher, 2011.

BEZERRA, Maria Augusta Rocha, et al. Acidentes domésticos em crianças: concepções práticas dos agentes comunitários de saúde. Cogitare Enferm. 2014 Out/Dez; 19(4):776-84.

BOMFIM, Gustavo Amarante. Metodologia para Desenvolvimento de Projetos. João Pessoa: Editora Universitária/UFPB, 1995.

\section{BRANDÃO, Eduardo Rangel. Sistematização do} Homem-Tarefa-Máquina (SHTM), 2012.

Disponível em:

https://pt.slideshare.net/eduardobrandao/sistematizao -do-sistema-homemtarefamquina-shtm. Acesso em 19 de abril de 2017.

BROOKE, John. SUS - A quick and dirty usability scale. 1986. Disponível em: http://dag.idi.ntnu.no/IT3402_2009/sus_background. 
pdf. Acesso em 20 de abril de 2017.

BUZAN, Tony. Mapas mentais e sua elaboração: um sistema definitivo de pensamento que transformará a sua vida. São Paulo: Cultrix, 2005.

CAVALCANTI, Janaina Ferreira. Análise ergonômica da sinalização de segurança: Um enfoque da ergonomia informacional e cultural. 229 f. Dissertação (Mestrado) - Curso de Engenharia de Produção, Universidade Federal de Pernambuco, Recife, 2003.

CUNHA, Karenine; MANTELLO, Paulo. 2014. Era uma Vez a Notícia: Storytelling como Técnica de Redação de Textos Jornalísticos. Comunicação Midiática, v. 9, n. 2, 2014.

KINDERMANN, Geraldo. Choque elétrico. 2 ed. Porto Alegre: Sagra Luzzatto, 2000.

LOBACH, Bernd. Design Industrial: Base para a configuração dos produtos industriais. Editora Blucher. São Paulo, 2000.

\section{MALACARNE, J. Mortes de crianças por} acidentes com eletricidade aumentam mais de 50\% no brasil. Crescer, 2016. Disponível em $<$ https://revistacrescer.globo.com/Criancas/Seguranc a/noticia/2016/03/mortes-de-criancas-por-acidentescom-eletricidade-aumentam-mais-de-50-nobrasil.html> Acesso em 10 de setembro de 2019.

MCDONAGH, D., \& DENTON, H. Exploring the degree to which individual students share a common perception of specific mood boards: Observations relating to teaching, learning and team-based design. Design Studies, 2005.

MICHINOV, N. Is electronic brainstorming or brainwriting the best way to improve creative performance in groups? an overlooked comparison of two idea-generation techniques. Journal of Applied Social Psychology, Wiley Online Library, v. 42, n. S1, p. E222-E243, 2012.

MORAES, Anamaria de; MONT'ALVÃO, Cláudia. Ergonomia: Conceitos e aplicações. 2. ed. Rio de Janeiro: 2ab, 2000.

PASCHOARELLI, Luis Carlos. Aspectos Ergonômicos e de Usabilidade no Design de Pegas e Empunhaduras. Estudos em Design. vol. 8. Rio de Janeiro: Abril, 2000.

PHEASANT, S. Bodyspace - Anthropometry, Ergonomics and Design of Work. Taylor \& Francis, 1996.
SANDERS, M.S.; McCORMICK, E. J. Human Error, Accidents, and Safety. In: SANDERS, M.S.; McCORMICK, E. J. Human Factors in Engineering and Design. 7 th ed. New York: McGraw-Hill, 1993. chap. 20, p. 655 - 695 .

SANTOS, M. A. da S. Choque elétrico, um verdadeiro perigo. Mundo Educação. Disponível em: <

http://mundoeducacao.bol.uol.com.br/fisica/choqueeletrico-um-verdadeiro-perigo.htm> Acesso em 10 de setembro de 2019.

VIANNA, Y.; VIANNA, M.; ADLER, I. K. Design thinking: inovação em negócios. Rio de Janeiro: MJV Press, 2012. 